\title{
ASPECTOS EVOLUTIVOS DO CONCEITO DE REGIONALIZAÇÃO EM SAÚDE
}

\author{
CÉLIA REGINA RODRIGUES GIL1
}

GIL, Célia Regina Rodrigues. Aspectos Evolutivos do Conceito de Regionalização em Saúde. Semina: Ci. Biol./Saúde, Londrina, v. 16, n. 2, p. 204-207, jun. 1995.

RESUMO : Este artigo visa discutir o conceito de Regionalização em Saúde em seu aspecto evolutivo, bem como a sua incorporaçăo pelo setor saúde. Inicialmente săo apresentados os conceitos de alguns autores, seguida de uma contextualização sobre a organizaçăo dos serviços de saúde no Brasil, desde o início do século. Relata o surgimento da regionalizaçăo como uma das propostas para a reorientaçăo da politica nacional de saúde brasileira. Finaliza com várias reflexões das diversas dimensóes contidas no processo atual de transiçăo que busca a reorganizaçăo dos serviços sob um paradigma que priorize a qualidade, a eqüidade e a humanização da assistência à saúde.

PALAVRAS-CHAVE: regionalizaçăo, distritalizaçăo, territorializaçăo, área de abrangencia e acesso.

\section{INTRODUÇÃOO}

O processo da Reforma Sanitária Brasileira tem colocado desafios importantes aos indivíduos que têm compromisso social com a democratização do Estado brasileiro e com a construção da consciência cidadă em uma sociedade marcadamente desigual como é a nossa.

No Setor Saúde, estes desafios se colocam hoje em diferentes espaços, quer sejam eles institucionais (serviços e universidades) ou da sociedade civil organizada (movimentos, associaçōes, entre outros).

Na América Latina, e particularmente no Brasil, pode-se dizer que há pelo menos dois pontos que determinam, nestes diferentes espaços, realidades tão comuns. Um deles é a conformação de nossa sociedade que, estruturada pelo capitalismo tardio e periféricodependente, apresenta fortes características sociais, políticas, econômicas e culturais calcadas nas diferenças sociais e no completo descompromisso com as politicas sociais e públicas - quer pelo Estado que năo as implementa, quer pela sociedade civil que, pelo seu baixo grau de organizaçăo, não as valoriza, não as reivindica e não as controla (COSTA, 1989 e TOMAZI, 1986).

Outro ponto é a influência do modelo de saúde flexneriano que, baseado num paradigma fundamentalmente biológico e quase mecanicista para a interpretação dos fenômenos vitais, gerou, entre outras coisas, o culto à doença e não à saúde e a devoção à tecnologia, sob a presunçáo ilusória de que ela seria o centro da atividade científica e de assistência à saúde (NOVAES, 1990). Este paradigma norteou a conformação dos modelos de organização dos serviços, dos currículos do ensino médico e das demais profissőes da saúde e da difusão da concepção biologicista e médico-hospitalocêntrica de saúde junto à população.

\section{REGIONALIZAÇÄO DOS SERVIÇOS DE SAÚDE}

A delimitação de um espaço geográfico para a organização dos serviços de saúde tem sido um dos critérios apontados para se obter a melhoria da qualidade da atenção à saúde prestada à população.

Quando se pensa na diretriz Regionalização dos Serviços de Saúde, alguns critérios imediatamente se associam a ela como facilidade de acesso, racionalização da oferta, processo de avaliação e equidade, entre outros.

O conceito de regionalização dos serviços já é apontado por Bertrand Dawson, do Conselho Consultivo Médico do Ministério da Saúde da Inglaterra, em 1920 (OPAS, 1988). Dawson define a regionalização como a forma de coordenar os aspectos preventivos e terapêuticos numa zona específica.

Propunha Dawson na década de 1910 em contraposição às recomendações de Flexner que

"... a medicina preventiva e a curativa năo podem ser separadas em virtude de nenhum principio sólido pois todos os planos de serviços médicos devem ser estreitamente coordenados. Alem disso, devem ser colocados dentro da esfera do médico generalista funçöes que abrangem a Medicina tanto para o indivíduo como para a comunidade..." e ainda, "... qualquer plano de serviços deve ser acessivel a todas as classes da comunidade..." (DAWSON apud NOVAES, 1990).

A regionalização é considerada como um esquema de implantação racional de recursos de saúde, organizados dentro de uma disposição hierárquica na qual seja possível oferecer uma assistência máxima nos centros primários e os demais serviços utilizados

\footnotetext{
1. Enfermeira Sanitarista, mestranda em Saúde Coletiva, Depto, Materno-Infantil e Saúde Comunitária/Universidade Estadual de Londrina, Caixa Postal 1562, Londrina-PR-Brasil, CEP 86038-440, Fone : (043) 321-2001 ramal 274.
} 
apropriadamente de acordo com as necessidades individuais do paciente. Somers e Somers (apud NOVAES, 1990) a definem como um sistema formal de apropriação de recursos, com distribuição geográfica dos estabelecimentos de saúde, dos recursos humanos e programas de atenção médica, com as diferentes atividades profissionais cobrindo todo o espectro da assistência integral; todos os acordos, conexöes e mecanismos de referência necessários para interrelacionar vários niveis e estabelecimentos, num conjunto coerente e capaz de servir todas as necessidades dos pacientes, dentro de uma base populacional definida (NOVAES, 1990).

Para Ginzberg (apud NOVAES, 1990), a regionalização implica a distribuiçăo de recursos ou serviços numa deteminada área, numa ordem que facilite o acesso, ofereça alta qualidade de serviços, baixo custo, grande eqüidade, com uma melhor e mais rápida resposta aos desejos e exigência dos consumidores (NOVAES, 1990).

A regionalizaçäo envolve sempre um ordenamento ou reordenamento de recursos com alteração das funções e das relaçōes entre os provedores de servicos de saúde. Para Guerra de Macedo (apud NOVAES, 1990), o sistema de saúde compreende a articulação de todos os recursos existentes numa zona para sua melhor utilização, adequação à realidade local $e$, sobretudo, o estabelecimento de uma relação de mútua responsabilidade com a população da área adstrita (CONFERÊNCIA NACIONAL DE SAÚDE, 1975).

Segundo Roberto Capote Mir,

"la organizacion de los servicios de salud cuenta con la regionalización y la descentralización como base fundamental. Esta debe tener en cuenta los criterios de las decisiones politico-administrativas, que a seu vez conforman los sistemas intermedios administrativos de los servicios - los senvicios locales de salud y la red de hospitales, todos ellos conformando la red de servicios que tendrá a su cargo no sólo los problemas de atención a la morbilidad, sino la organización de las actividades en funcion de los problemas locales identificados, dentro de normas nacionales, estatales o provincial y locales, que permita desarrollar um 'árbol de objetivos' sanitáioepiderniologico, nacional, intermedio y local y un 'árbol de decisiones' con los mismos niveles" (NOVAES \& CAPOTE MIR, 1987).

\section{ORGANIZAÇÃO DOS SERVIÇOS DE SAÚDE NO BRASIL}

No Brasil, a lógica da organização dos serviços de saúde sempre esteve sob a égide do capital.

Do início até meados do século, a economia esteve dominada por um modelo agroexportador fortemente assentado no café. Por essa razão, o que se exigia do sistema de saúde era, sobretudo, uma política de saneamento dos espaços de circulaçăo das mercadorias exportáveis e a erradicação ou controle de doenças que poderiam prejudicar a exportaçäo através de práticas de saúde pública de caráter campanhista e pontual, com objetivo de controlar a "saúde dos portos" (BRAGA \& PAULA, 1981).

Mais adiante, com o crescente avanço da industrialização do país, a prática que se legitima com o apoio do Estado, é a oriunda da Previdência Social que se caracterizava pelo atendimento clínico, individual, curativo e predominantemente privado e hospitalar.

O importante, então, já não é sanear o espaço de circulação das mercadorias, mas atuar sobre o corpo do trabalhador, mantendo e restaurando sua capacidade reprodutiva (OLIVEIRA \& TEIXEIRA, 1986).

Somente na década de 70 é que se começa a gestar no Brasil novas bases conceituais para a saúde. A formulaçăo de propostas altemativas para o setor, voltadas não ao lucro, mas às necessidades de saúde da população, traz em seu bojo a experimentação de novos modelos assistenciais que serviriam, a posterior, em importantes substratos para as propostas da Reforma Sanitária Brasileira (ESCOREL, 1987).

Durante este período, principalmente no âmbito dos Departamentos de Medicina Preventiva das Universidades, desenvolveram-se estudos, análises e reflexōes criticas acerca do sistema de saúde vigente e a formulação de propostas alternativas para o setor que se iniciam através de algumas experiências isoladas no país, como foi o caso de Londrina, Campinas e Montes Claros. Em meados da década estas se multiplicam tornando-se um "locus" importante de reflexöes e fertilizaçōes das idéias em tomo de uma nova modalidade de assistência.

Ao final da década, com a proposta intemacional dos cuidados primários, acordada em Aima-Ata, 1978. começa a ocorrer a expansão desta modalidade de assistência. A Atençăo Primária à Saúde (OPAS, 1978) que tinha como princípios norteadores a hierarquização, a regionalização, a racionalização e integraçăo do serviços com um sistema de referência e contrareferência entre os diversos niveis de assistência, trazia em seu bojo o privilegiamento das açōes ambulatoriais - resgate da prática generalista e a adequação tecnológica.

$\mathrm{Na}$ década de 80 , novos rumos na política de saúde se conformam. Durante este periodo, vários acontecimentos constituíram um movimento sinérgico de transformaçôes no cenário sanitário. Resumidamente, pode-se apontar a descentralização dos serviços de saúde do âmbito estadual para o municipal; a proposta das Ações Integradas de Saúde como estratégia de reorganização dos serviços; o advento da Nova República e a realização da 8 a. Conferência Nacional de Saúde ponto de inflexão de bastante significado para a história do movimento político pela reformulaçăo do sistema nacional de saúde. A elaboração e aprovaçâo da nova Constituição Federal, em 1988, também significou um saldo positivo, ainda que modesto, para o movimento pela Reforma Sanitária.

A década de 80 termina apresentando o Sistema Único de Saúde - SUS no cenário nacional como um passo a mais em direção à proposta, representando uma nova formulação política e organizacional para o reordenamento dos serviços de saúde, estabelecida pela Constituição de 1988. Segue a mesma doutrina e os mesmos princípios organizativos em todo o território nacional, sob a responsabilidade das três esferas de govemo: federal, estadual e municipal.

As açōes de saúde a serem desenvolvidas pelo SUS deverấo estar voltadas para um modelo de atenção integral à saúde, com a incorporação progressiva de açōes de promoção e proteçăo, ao lado daquelas propriamente ditas de recuperação (BRASIL, 1990).

Para que isso ocorra, há que se conhecer as principais caracteristicas do perfil epidemiológico da população, as condições sócio-econômicas e culturais da comunidade e suas necessidades de saúde. 


\section{REGIONALIZAÇÃO E OS SERVIÇOS DE SAÚDE NO BRASIL}

A regionalizaçăo como proposta para a reorientação da política nacional de saúde aparece, no Brasil, durante a 111 Conferência Nacional de Saúde, realizada em 1963. Através de um discurso sanitaristadesenvolvimentista, o governo propunha medidas que incluíam a simplificação da atençäo médica, a regionalização, hierarquizacão e descentralização sob a forma de municipalizaçäo dos serviços de saúde.

Após o golpe militar, esta temática é retomada em meados da década de 70 , porém sem o caráter desenvolvimentista, populista e nacionalista que servia a interesses mais globais das classes dominantes. Elas reaparecem, desta feita, servindo aos interesses corporativo-privatistas da medicina e aos interesses imediatos do capital (LUZ, 1986).

O modelo médico-assistencial privatista foi um modelo que separou a atenção à saúde das pessoas tarefa do setor privado, mediado pela Previdência Social, das ações de saúde coletiva - incumbência do complexo Ministério/Secretarias de Estado da Saúde.

Paralelamente às determinações econômicas internas, no cenário internacional da saúde, a doutrina dos cuidados primários em saúde e o momento racionalizador do planejamento da saúde expressos através da técnica CENDES/OPS (MENDES, 1987), trazem o conceito de áreas programáticas para o interior dos serviços de saúde. Criam-se as Unidades de Planejamento nas Secretarias Estaduais de Saúde cujo papel era organizar a oferta de assistência médica simplificada à população não integrante do processo produtivo, ou seja, às populaçōes urbano-periféricas e rurais dando inicio a um processo embrionário de desconcentração administrativa dessas instituiçōes através da criação de estruturas regionalizadas.

Neste período, a $\vee$ Conferência Nacional de Saúde, realizada em 1975, reitera a importância da área programática e a define como sendo a região, conjunto de regiōes ou de micro-regiões, municipio ou conjunto de municípios para os quais se estabelece um diagnóstico e uma programação em saúde (CONFERENCIA NACIONAL DE SAUDE, 1975).

Ainda sob a ótica da desconcentração administrativa e da racionalizaçāo dos recursos, ocorre no Brașjl a implantaçäo dos programas de extensăo de cobertura, dos quais o mais importante foi o PIASS Programa de Interiorização das Açōes de Saúde e de Saneamento, discutido, inclusive, durante a VI Conferência Nacional de Saúde em 1977 (CONFERENCIA NACIONAL DE SAÚDE, 1977).

Em 1978, a regionalização dos serviços de saúde é colocada como uma das diretrizes da Atenção Primária à Saúde durante a Conferência Internacional de AlmaAta.

No início da década de 1980 , por ocasião da V11 Conferência Nacional de Saúde, a regionalizaçăo aparece como proposta para a organização dos serviços de saúde. O conceito de regionalização é definido como sendo "... um processo de des-centralizaçăo com o objetivo de hierarquizar, disciplinar e operar uma rede de serviços de saúde, sob a forma de complexidade crescente, de acordo com as necessidades da populaçăo." (CONFERÊNCIA NACIONAL DE SAÚDE,
1980)

A partir dai a regionalização dos serviços de saúde é incorporada nas diretrizes gerais das propostas governamentais de reorganização do setor saúde.

O Sistema Único de Saúde - SUS reitera a importảncia da implementação da rede de serviços regionalizada como uma das medidas para melhorar a qualidade e resolutividade dos serviços e também para obter um maior conhecimento dos problemas de saúde de uma área delimitada.

Na construção de novos paradigmas conceituais e operacionais que contribuam para a legitimação das propostas da Reforma Sanitária, surgem algumas reflexōes teóricas importantes. Entre elas a do Distrito Sanitário como processo social de mudança que tem trazido várias contribuiçōes importantes para a reorganização do serviços de saúde e, entre elas, a importância da regionalizaçăo sob um novo enfoque : 0 de território-processo. $\mathrm{Na}$ concepçăo dos Distritos Sanitários ou Sistemas Locais de Saúde, a regionalização que antes era entendida fundamentalmente enquanto área de abrangência de um serviço de saúde, limitada a uma visão geográficotopográfica, passa a ser trabalhada enquanto uma região geográfica onde estão contidas várias dimensōes : uma dimensão técnica, uma dimensão política e uma dimensão ideológica. Nesta perspectiva, é de extrema importância que a regionalização não fique reduzida a demarcações ou modelos teóricos, mas que seja concebida como um processo que contemple as distintas realidades locais, com suas dinâmicas sociais próprias (MENDES, 1993).

Quando se assume esta concepção de território como norteadora da reorganização dos serviços de saúde, há, como consequência, uma opção pela aproximação da construção da consciência-cidadã do ser humano, atualmente reduzida, no caso particular da saúde, à dimensão de usuários dos serviços (ausência de percepção de sua condição de sujeito social) ou, quando muito, à dimensăo de consumidor dos serviços (percebe os direitos sociais como dádivas e nunca como conquista) (LABRA, 1993).

O cidadão (GOULART, 1993) é aquele que cons-cientemente se apropria dos direitos conquistados e luta coletivamente pela ampliaçăo desses direitos na busca de valores como a dignidade e liberdade.

\section{CONCLUSÃO}

Pode-se observar, pelo exposto acima, que o conceito de Regionalizaçăo vem incorporando ingredientes sociais importantes para a reflexão sobre a reorganizaçāo dos serviços de saúde.

O Sistema Único de Saúde - SUS recupera aspectos importantes já apontados por Dawson no início do século e por outros autores no decorrer do periodo e que não tinham sido incorporados nas políticas oficiais do Brasil. O conceito de regionalizaçăo, esteve até esse momento, predominantemente vinculado à visão racionalizadora dos serviços e limitado apenas à dimensăo geográfica.

$\mathrm{Na}$ atual concepção de regionalizaçăo em que o enfoque prioriza a visão do território enquanto um processo em construção, resgatam-se aí importantes 
ingredientes para o repensar das práticas em saúde : 0 social e o cultural.

Sob este enfoque, a ternitorialização, ao contrário do que é feito hoje, necessita de instrumentos que contribuam para uma maior reflexão e compreensăo das diversas dimensões contidas nestes espaços.

Neste sentido, considerando a evolução histórica dos modelos que nortearam as práticas de assistência à saúde e que foram determinados, como exposto anteriormente, pelo paradigma biologicista e considerando-se o processo atual de transição que busca a reorganizaçăo dos serviços sob um paradigma que priorize a qualidade, a eqüidade $e$ a humanizaçåo da assistência, pode-se concluir que a formação dos futuros profissionais de saúde nảo pode continuar pautada em práticas predominantemente curativas e traduzidas em açōes terapêuticas isoladas.

O desafio que se coloca hoje, no campo do ensino, é o de se avançar no processo de reflexăo, de modo a se obterem ações de saúde que se traduzam em práticas integralizadoras, multiprofissionais e compartidas com outras áreas do conhecimento. Somente assim é que a academia poderá dar um salto qualitativo importante com vistas a contribuir com a reorganizaçăo dos serviços e das práticas de atençăo à saúde.

GIL, Célia Regina Rodrigues. Health system regionalization: evolutive aspects of the concept. Semina: $\mathrm{Ci}$. Biol./Saúde. Londrina, v. 16, n. 2, p. 204-207, Jun. 1995.

ABSTRACT: This article aims to discuss the concept of health regionalization and its evolutive aspects, as well as its incorporation by the health system. Iniatially, a review of some authors is presented, followed by a review about the organization of health services in Brazil since the beginning of this century. It describes the stablishment of regionalization as a new proposal to reorientate the Brasilian National Health Policy. The article, ends by discussing the various dimensions involved within the present process of transition from centralized to a regionalized system which aims to reorganize the services with priority to quality, equidity and humanization of health assistance.

KEY-WORDS: Regionalization, Sanitary District, Area of influence, Territory.

\section{REFERÊNCIAS BIBLIOGRÁFICAS}

BRAGA, J.C.; PAULA, S. Góes de. Saúde o Previdéncia. São Paulo. Hucitec, [19].

BRASIL. Ministério da Saúde. Secretaria Nacional de Assistência à Saúde. ABC đo SUS: doutrinas e princlpios. Brasilia : Ministério, 1990.

CONFERÊNCIA NACIONAL DE SAÚDE, 5, Brasilia, 1975. Anais... Brasilia: Ministério da Saúde, 1975.

CONFERÉNCIA NACIONAL DE SAÚDE, 6, Brasilia, 1977. Anais... Brasilia: Ministério da Saúde, 1977.

CONFERÊNCIA NACIONAL DE SAÚDE; 7 , Brasilia, 1980. Anais... Brasilia: Ministério da saúde, 1980.

COSTA N. do R. (Org.). Demandas populares, polficas públicas e saúde, Petrópolis: Vozes, 1989.

ESCOREL, S. Reviravolta na Saúde: origem e articuleçăo do movimento sanitário. Rio de Janeiro: [s.n.], 1987. Tese (Mestrado) - ENSPIFIOCRUZ, 1987.

GOULART, F.A. Movimentos sociais, cidadania e saúde. Anotaçōes pertinentes à conjuntura atuat, Revista Saúdo em Debate, n. 39, 1993.

LABRA, M.E. El Sistema de Senvicios de Salud de Brasil. março de 1993. (Mimeo)

LUZ, M.T. As Instiftuiçöes Médicas no Brasiv: instituiçz̄es e estratégias de hegemonia. Rio de Janeiro: Graal, 1986.

MENDES, E.V. (Org.) Distrito Sanitário: o processo social de mudança das práticas sanitárias do Sistema Único de Saúde. São Paulo: Hucitec, 1993. Cap. 1: as políticas de saúde no Brasil nos anos 80: a conformaçäo da reforma sanitária e a construçăo da hegemonia do projeto neoliberal. p. $19-92$

MENDES, E.V. Organizaçăo de Sistemas de Saúde. Desafios e perspectivas. In: CONGRESSO MEDICO, 3 , 1993, Brasília. (Mimeo)

MENDES, E.V. O sistema unificado e descentralizado de saúde

no atual contexto da Reforma Sanitária Brasileira. In: SEMINARIO INTERINSTITUCIONAL SOBRE A REFORMA SANITARIA E A ORGANIZACGAO DOS SERVICYOS DE SAÚDE, 1987, Natal. (Mimeo)

O PROCESSO SOCIAL DE DISTRITALIZACÃO DA SAÚDE, In: SEMINARIO INTERINSTITUCIONAL SOBRE A REFORMA SANITARIA E A ORGANIZAÇĂO DOS SERVIÇOS DE SAÚDE, 1987, Natal. p.93-168. Cap. 3. (Mimeo).

NOVAES, H.M. Açoes integradas nos sistemas locajs do saúde SILOS. Săo Paulo: Pioneira, 1990.

NOVAES, M.M. 2 CAPOTE MIR, R. Sistomas localos do Servicios como Pollitica de Regionalizacion de la Salud: Buenos Aires: OPAS, 1987.

OLIVEIRA, J.; FLEURY TEIKEIRA, S. Proviolencia Social no Brasil. Rio de Janeiro : Vozes/ABRASCO, 1986.

OPAS. El desarrollo y fortalecimiento de los Sistomas Localos de Salud en la transformacion de los Sistemas Nacionalos de salud. Washington: La organizacion, 1988.

OPAS. Extension de la cobertura de servicios de safud con las estratégias de atencion primária y participacion de la comunidad. Washington: [s.n.], 1978. (Mimeo)

TOMAZI, Z.T. Saúde e Estado Brasileiro. Cadernos de Educaçăo Polltica. [s.1.]: Global, 1986. 